\title{
Produção acadêmica sobre masculinidades nos anais do congresso brasileiro/internacional de ciências do esporte
}

\section{RESUMO}

A proposta deste estudo foi de mapear e problematizar a produção acadêmica relativa aos estudos sobre masculinidades no campo da Educação Física, por meio de um levantamento bibliográfico nos anais do Congresso Brasileiro/Internacional de Ciências do Esporte.Buscamos discutir significações da categoria masculinidade presentes nos trabalhos publicados nos encontros nacionais dos últimos quinze anos.Selecionamos 21 textos e, entre os resultados, identificamos a prevalência nas práticas corporais e esportivas de uma masculinidade hegemônica ou de outras expressões que denotavam uma dominação do masculino, visibilizando bem pouco os processos de resistência de masculinidades outras nestes espaços, o que vemos como uma lacuna a ser preenchida pelos futuros trabalhos. Finalizamos o trabalho apontando caminhos teóricos e empíricos, que podem ser potentes e produtivos para as futuras pesquisas dos estudos sobre masculinidades na área da Educação Física.

PALAVRAS-CHAVE:Masculinidade; Gênero; Educação física; Revisão acadêmica
João Gabriel Marques Portilho

Licenciado em Educação Física pela Universidade Federal do Rio de Janeiro (UFRJ)

Universidade Federal do Rio de Janeiro, Escola de Educação Física e Desportos, Rio de Janeiro, Brasil joaogportilho@gmail.com

○ https://orcid.org/0000-0002-9643-7033

\section{Leandro Teofilo de Brito} Doutorado em Educação pela Universidade do Estado do Rio de Janeiro (UERJ) Universidade Federal do Rio de Janeiro, Escola de Educação Física e Desportos, Rio de Janeiro, Brasil teofilo.leandro@gmail.com.br ○ https://orcid.org/0000-0002-9123-5280

Ana Paula da Silva Santos Doutorado em Educação pela Pontificie Universidade Católica do Rio de Janeiro

(PUC-RIO)

Universidade Estácio de Sá, Rio de Janeiro, Brasil

apss.sol@gmail.com ๑ https://orcid.org/0000-0003-0755-2484 
Academic production on masculinities in the annals of the brazilian/international congress of sport sciences

\begin{abstract}
The purpose of this study was to map and problematize the academic production related to studies on masculinities in the field of Physical Education, through a bibliographic survey in the annals of the Brazilian/International Congress on Sports Sciences. We seek to discuss meanings of the masculinity category present in the works published in the national meetings of the last fifteen years. We selected 21 texts and, among the results, we identified the prevalence in the body and sports practices of a hegemonic masculinity or other expressions that denoted a male domination, showing very little the resistance processes of other masculinities in these spaces, what we see as a gap to be filled by future work. We ended the work by pointing out theoretical and empirical paths, which can be powerful and productive for future research on studies on masculinities in the area of Physical Education.
\end{abstract}

KEYWORDS:Masculinity; Gender; Physical education; Academic review

\title{
Producción académica sobre masculinidades en los anales del congreso brasileño/internacional
} de ciencias del deporte

\section{RESUMEN}

El propósito de este estudio fue mapear y problematizar la producción académica relacionada con los estudios sobre masculinidades en el campo de la Educación Física, a través de un levantamiento bibliográfico en los anales del Congreso Brasileño/Internacional de Ciencias del Deporte. Buscamos discutir los significados de la categoría de masculinidad presentes en los trabajos publicados en los encuentros nacionales de los últimos quince años. Seleccionamos 21 textos y, entre los resultados, identificamos la prevalencia en el cuerpo y las prácticas deportivas de una masculinidad hegemónica $u$ otras expresiones que denotaban una dominación masculina, mostrando muy poco los procesos de resistencia de otras masculinidades en estos espacios, lo que vemos como un vacío que debe llenarse con trabajos futuros. Terminamos el trabajo señalando caminos teóricos y empíricos, que pueden ser poderosos y productivos para futuras investigaciones sobre estudios sobre masculinidades en el área de la Educación Física.

PALABRAS-CLAVE:Masculinidad; Género; Educación fisica; Revisión académica 


\section{INTRODUÇÃO}

No ano de 2019, o portal Papo de homem ${ }^{1}$, página que se dedica à discussão sobre o temada masculinidade por meio de matérias e reportagens, publicou uma pesquisa nacional intitulada $\mathrm{O}$ silêncio dos homens ${ }^{2}$, que, posteriormente, deu nome também a um documentário ${ }^{3}$. Esta pesquisa nacional alcançou 47.002 respostas de pessoas por todo o Brasil, agrupando dados sobre as construções e percepções da masculinidade na sociedade. Entre os resultados, os homens respondentes afirmaram terem sido ensinados durante a infầncia e adolescência a: serem bem sucedidos profissionalmente (85\%), não se comportarem de modo que pareçam femininos (78\%), serem fisicamente fortes (73\%), serem responsáveis pelo sustento financeiro da família (67\%), não expressarem emoções (57\%) e darem em cima das mulheres sempre que possível (48\%). Esta pesquisa teve como objetivo central visibilizar o debate contemporâneo sobre a chamada masculinidade tóxica, que diz respeito aos modos normativos de "ser homem" presentes desde cedo na criação e educação de meninos e jovens, e que hoje, mais do que nunca, sabe-se que é maléfica para os próprios homens ao gerar desequilíbrio e desordem emocional para os mesmos nas relações sociais (CASTRO, 2018).

A masculinidade tóxica é uma enunciação contemporânea muito próxima aos sentidosda teorização da masculinidade hegemônica, que é significada como um padrão de práticas atravessado por relações de poder, que enfatiza a perpetuação da dominação dos homens sobre as mulheres e, sobretudo, a criação de uma hierarquia entre masculinidades (KIMMEL, 1998; CONNELL, 2003; CONNELL, 2016). Nesta ordem hierárquica, a masculinidade hegemônica ocupa o topo na estrutura das relações de gênero, assumindo uma distinção para as outras masculinidades tidas como subalternizadas e nomeadas como cúmplices, marginalizadas e subordinadas (CONNELL, 2003). Neste sentido, facilmente associamos o debate sobre as masculinidades com o campo das práticas corporais e esportivas, pois nos dados da pesquisa mencionada "não parecerem femininos" e "serem fortes" são enunciações reiteradas nos processos de regulação dos corpos de meninos e jovens.

Para Connell (2016), a corporificação das masculinidades é um processo que atravessa a infância, a adolescência e a idade adulta ao enfatizar o encontro sexual, as atividades físicas e os esportes como meios de diferenciação entre masculinidade hegemônica e masculinidades subalternizadas. Considerando o esporte como uma área de domínio masculino, Dunning (2014) afirma que o caráter patriarcal do esporte moderno conserva a hegemonia masculina neste espaço, produzindo e reproduzindo as identidades assumidas pelos homens no social. Nos estudos de gênero na Educação Física, a categoria masculinidade

${ }^{1}$ Portal Papo de homem. Disponível em: https://bit.ly/2BwVYvX. Acesso em: 26 de jul. 2020.

${ }^{2}$ Pesquisa O silêncio dos homens. Disponível em: https://bit.ly/3eXnkZD. Acesso em: 26 de jul. 2020.

${ }^{3}$ Documentário O silêncio dos homens. Disponível em: https://bit.ly/3g4syUR. Acesso em: 26 de jul. 2020. 
é uma vertente em desenvolvimento e que, em alguma medida, pode ser considerada subalternizada frente a produção da área sobre as mulheres e o feminino (GOELLNER, 2013). De todo modo, trabalhos sobre essa temática vem sendo desenvolvidos por pesquisadores/as da área que apostam na discussão sobre as masculinidades via práticas corporais e esportivas (MORAES E SILVA; CÉSAR, 2012; BRITO; SANTOS, 2013; SILVA; FERREIRA, 2016; WENETZ; MACEDO, 2019; SERRANO; CAMINHA; GOMES, 2020; entre outros/as), contribuindo com olhares mais amplos e complexos para os estudos de gênero na Educação Física.

Dois levantamentos bibliográficos sobre a categoria masculinidade focalizaram publicações de artigos em periódicos da área da Educação Física e da Educação (BRITO; LEITE, 2017, 2019) e, neste estudo, daremos continuidade a essa discussão ao focalizarmos os anais do principal evento científico da área de Educação Física: Congresso Brasileiro de Ciências do Esporte/Congresso Internacional de Ciências do Esporte (CONBRACE/CONICE). Assim, buscamos mapear e problematizar a produção acadêmica sobre a categoria masculinidade no campo de estudos da Educação Física, por meio de um levantamento nos anais do CONBRACE/CONICE, para discutir significações desta temática presentes nos trabalhos publicados nos encontros nacionais dos últimos quinze anos. Na sequência, discutiremos os procedimentos que realizamos para o levantamento dos trabalhos.

\section{SOBRE O LEVANTAMENTO}

Criado em 1978, o Colégio Brasileiro de Ciências do Esporte ${ }^{4}$ (CBCE), é uma entidade científica que articula a convenção de pesquisadores/as da área da Educação Física e das Ciências do Esporte. O CBCE se organiza em Secretarias Estaduais e Grupos de Trabalhos Temáticos (GTT) - total de treze ${ }^{5}$-, que são norteados por uma Direção Nacional com representação em vários órgãos governamentais e vinculada à Sociedade Brasileira para o Progresso da Ciência (SBPC). A entidade é responsável pela elaboração e realização do CONBRACE/CONICE, principal evento científico do país na área da Educação Física, e responsável também pelos congressos estaduais e regionais, assim como por encontros dos GTTs, que contam com ampla participação da comunidade científica e acadêmica da área.

No ano de 2013 houve parecer favorável à criação do GTT 07 - Gênero ${ }^{6}$, que buscou concentrar a discussão sobre gênero em um polo específico, propiciando que pesquisadores/as da área pudessem

${ }^{4}$ Página do CBCE. Disponível em: https://bit.ly/3jObqVw. Acesso em: 27 de jul. 2020.

${ }^{5}$ GTT 01 - Atividade Física e Saúde; GTT 02 - Comunicação e Mídia; GTT 03 - Corpo e Cultura; GTT 04 Epistemologia; GTT 05 - Escola; GTT 06 - Formação Profis sional e Mundo do Trabalho; GTT 07 - Gênero; GTT 08 - Inclusão e Diferença; GTT 09 - Lazer e Sociedade; GTT 10 - Memórias da Educação Física e Esporte; GTT 11 - Movimentos Sociais; GTT 12 - Políticas Públicas; GTT 13 - Treinamento Esportivo.

${ }^{6}$ Análise técnica e parecer quanto a solicitação de criação de novo GTT - "Gênero" no CBCE. Disponível em: https://bit.ly/2P3YNrC. Acesso em: 28 de jul. 2020. 
compartilhar interesses e difundir conhecimentos em comum acerca do tema. Assim, no XIX CONBRACE e V CONICE, que ocorreu no ano de 2015 em Vitória no Espírito Santo - ES, o GTT 07 iniciou sua história no evento. Conforme informações presentes na página da entidade ${ }^{7}$, o GTT de gênero contempla estudos sobre os processos específicos através dos quais as práticas esportivas e corporais produzem e transformam os sentidos do feminino e do masculino, que tenham por base suportes teóricos-metodológicos de diferentes campos disciplinares em sua interface com Educação Física e Ciências do Esporte. Entretanto, ainda que o debate sobre gênero tenha sido direcionado para um GTT específico apenas no ano de 2015, trabalhos sobre a temática já eram difundidos no evento nos anos anteriores por outros GTTs, conforme discutiremos no mapeamento e problematização dos trabalhos localizados no levantamento.

Assim, realizamos um levantamento bibliográfico nos anais do CONBRACE/CONICE, focalizando os encontros nacionais entre 2005 e 2019. Nossa escolha pelos eventos nacionais se justifica por serem encontros que concentram um número maior de participantes e, consequentemente, de trabalhos sistematizados dentro dos temas dos GTTs, que, por vezes, nos encontros regionais podem ser descentrados, conforme demanda de participação e envio de propostas de trabalhos. O período de 2005 a 2019, abarca, aproximadamente, os últimos quinze anos de produção acadêmica no evento, que representa um total de oito encontros nacionais - 2005, 2007, 2009, 2011, 2013, 2015, 2017, 2019 - e que julgamos como um recorte de tempo potente e produtivo para problematizar os trabalhos sobre a categoria masculinidade. Neste contexto, destacamos que os estudos sobre masculinidades se sistematizaram na produção acadêmica nacional da área de ciências humanas e sociais na segunda metade da década de 1990 (MEDRADO; LYRA, 2008), informação que também justifica a escolha deste recorte de tempo.

A busca dos trabalhos ocorreu nos anais eletrônicos do evento ${ }^{8}$ e utilizamos para essa busca os descritores masculinidade e masculino/a, assim como como menino, garoto, rapaz e homem e suas flexões no plural para a localização dos textos. Selecionamos os trabalhos pelos títulos e caso surgisse alguma dúvida era feita a leitura do resumo e/ou do texto completo para identificar discussões sobre as masculinidades em seu conteúdo. Alguns trabalhos localizados traziam estes descritores nos títulos, resumos ou conteúdos, porém não desenvolviam discussão específica sobre a categoria masculinidade ou mesmo sobre gênero e sexualidade e descartamos. Também optamos pela seleção de trabalhos completos e resumos expandidos ${ }^{9}$, que dizem respeito às comunicações orais, descartando os resumos simples, pois

${ }^{7}$ GTT 07 - Gênero. Disponível em: https://bit.ly/2WYwT4z. Acesso em: 28 de jul. 2020.

${ }^{8}$ Anais CBCE. Disponível em: https://bit.ly/30T8hLO. Acesso em: 28 de jul. 2020.

${ }^{9}$ No XX CONBRACE e VII CONICE, evento realizado no ano de 2017 em Goiânia - GO, os trabalhos da modalidade comunicação oral passaram ser publicados como resumos expandidos. 
consideramos que as discussões destas modalidades trazem informações mais amplas para o mapeamento e problematização dos textos. No total, revisamos 4556 trabalhos e selecionamos 21 trabalhos.

Após isso, realizamos um mapeamento dos trabalhos destacando informações como títulos, ano de publicação, GTT em que se localizou, autoria, temática, noção de masculinidade, metodologia e principais resultados, que apresentaremos num quadro. Com essas informações, problematizaremos os trabalhos selecionados e mapeados ao identificarmos suas ênfases, recorrências e lacunas, configurando revisão do que se tem produzido sobre os estudos das masculinidades no CONBRACE/CONICE. Por fim, apontaremos caminhos para as futuras pesquisas sobre a temática na área da Educação Física.

\section{SIGNIFICAÇÕES DAS MASCULINIDADES NOS ANAIS DO CONBRACE/CONICE}

Para iniciar nossa problematização sobre os trabalhos, apresentaremos os textos selecionados e mapeados em um quadro com informações que serão debatidas na sequência:

Quadro 1 - Trabalhos selecionados

\begin{tabular}{|c|c|}
\hline \multicolumn{2}{|c|}{$\begin{array}{l}\text { Os discursos corporais produzidos pelos } \\
\text { desenhos animados "Popeye" e "Liga da Justiça" }\end{array}$} \\
\hline Ano: 2005 & GTT: Corpo e cultura \\
\hline \multicolumn{2}{|c|}{ Autoria: Daniel KrásCarrazzoni e Ileana Wenetz } \\
\hline Temática: Gênero e desenhos animados & Metodologia: Análise de artefatos culturais \\
\hline \multicolumn{2}{|c|}{ Noção de masculinidade: Louro; Smith; Fraga } \\
\hline \multicolumn{2}{|c|}{$\begin{array}{l}\text { Principais resultados: Os desenhos animados analisados apresentaram uma visão cultural do corpo } \\
\text { embasada na estética e na beleza, diferenciando gênero masculino e feminino }\end{array}$} \\
\hline \multicolumn{2}{|c|}{ De menino a homem: a mídia e a construção de masculinidades esportivas } \\
\hline Ano: 2007 & GTT: Comunicação e mídia \\
\hline \multicolumn{2}{|c|}{$\begin{array}{l}\text { Autoria: Jorge DorfmanKnijnik; Eduardo Vinicius Mota e Silva; Janisio Xavier de Souza; Antenor Magno } \\
\text { da Silva Neto; Judá Eckert Berto; Neilton Souza Ferreira Júnior; Paulo César Falcão Delfino; Adriano } \\
\text { Cruz da Silva; Cristina Vieira dos Santos }\end{array}$} \\
\hline Temática: Masculinidades e mídia & Metodologia: Análise do discurso \\
\hline \multicolumn{2}{|c|}{ Noção de masculinidade: Connell; Terret; Rial } \\
\hline \multicolumn{2}{|c|}{$\begin{array}{l}\text { Principais resultados: Os discursos dos radialistas mostraram os sujeitos presos a normas de gênero } \\
\text { limitantes, estereotipadas e preconceituosas, que pretendem restringir os jeitos de ser dos atletas }\end{array}$} \\
\hline \multicolumn{2}{|c|}{$\begin{array}{l}\text { Corpo, cultura e masculinidade: os discursos sobre um } \\
\text { "novo" tipo de homem na mídia impressa, o "metrosse xual" }\end{array}$} \\
\hline Ano: 2009 & GTT: Corpo e cultura \\
\hline \multicolumn{2}{|l|}{ Autoria: Marcos Roberto Godoi } \\
\hline Temática: Masculinidades e mídia & Metodologia: Análise de documentos \\
\hline \multicolumn{2}{|l|}{ Noção de masculinidade: Kimmel; Nolasco } \\
\hline \multicolumn{2}{|c|}{$\begin{array}{l}\text { Principais resultados: As revistas analisadas trouxeram a enunciação metrossexual alinhada com o sistema } \\
\text { de produção capitalista }\end{array}$} \\
\hline \multicolumn{2}{|c|}{ A separação de meninos e meninas na Educação Física escolar: marcas de gênero } \\
\hline Ano: 2009 & GTT: Corpo e cultura \\
\hline
\end{tabular}




\begin{tabular}{|c|c|}
\hline \multicolumn{2}{|l|}{ Autoria: Priscila Gomes Dornelles } \\
\hline $\begin{array}{l}\text { Temática: Gênero, sexualidade e Educação } \\
\text { Física escolar }\end{array}$ & Metodologia: Questionários e entrevistas \\
\hline \multicolumn{2}{|c|}{ Noção de masculinidade: Scott; Foucault; Silva; Louro; Meyer; Gomes } \\
\hline \multicolumn{2}{|c|}{$\begin{array}{l}\text { Principais resultados: A escola e a disciplina de Educação Física legitimam formas de ser menino e de ser } \\
\text { menina num processo de significação produz hierarquias e desigualdades }\end{array}$} \\
\hline \multicolumn{2}{|c|}{ Sexualidade e educação física escolar: articulações (im)possíveis? } \\
\hline Ano: 2011 & GTT: Escola \\
\hline \multicolumn{2}{|l|}{ Autoria: Ileana Wenetz e Priscila Gomes Dornelles } \\
\hline $\begin{array}{l}\text { Temática: Gênero, sexualidade e Educação } \\
\text { Física escolar }\end{array}$ & Metodologia:Entrevistas \\
\hline \multicolumn{2}{|l|}{ Noção de masculinidade: Louro } \\
\hline \multicolumn{2}{|c|}{$\begin{array}{l}\text { Principais resultados: A categoria sexualidade dimensiona os sentidos sobre corpos e gênero na Educação } \\
\text { Física e meninos e meninas desviantes são, conforme as falas de docentes, realocados para garantir a } \\
\text { coerência de gênero }\end{array}$} \\
\hline \multicolumn{2}{|c|}{$\begin{array}{c}\text { Histórias de vida e o processo de subjetivação das experiências de } \\
\text { adolescentes aprendizes com um esporte masculinizado }\end{array}$} \\
\hline Ano: 2011 & GTT: Corpo e cultura \\
\hline \multicolumn{2}{|c|}{ Autoria: Victor José Machado de Oliveira e Erineusa Maria da Silva } \\
\hline Temática: Gênero e iniciação esportiva & Metodologia: Histórias de vida \\
\hline \multicolumn{2}{|c|}{ Noção de masculinidade: Scott; Louro; Bourdieu } \\
\hline \multicolumn{2}{|c|}{$\begin{array}{l}\text { Principais resultados: O futebol como um fenômeno social que atende à construção da identidade nacional } \\
\text { e afetam os sujeitos praticantes, que sofrem inculcações provindas desse fenômeno reforçadamente } \\
\text { masculinizado }\end{array}$} \\
\hline \multicolumn{2}{|c|}{$\begin{array}{l}\text { Modelos de identidades masculinas na propaganda de desodorante: novos } \\
\text { deslocamentos }\end{array}$} \\
\hline Ano: 2011 & GTT: Comunicação e mídia \\
\hline \multicolumn{2}{|c|}{ Autoria: Caio Anawate, Kuri Milito e Carlos José Martins } \\
\hline Temática: Masculinidades e mídia & Metodologia: Análise de imagens \\
\hline \multicolumn{2}{|c|}{ Noção de masculinidade: Garcia; Hoff; Nascimento; Nunes; Veríssimo } \\
\hline \multicolumn{2}{|c|}{$\begin{array}{l}\text { Principais resultados: } \mathrm{O} \text { trabalho analisa uma propaganda do desodorante com modelos caracterizados } \\
\text { pela virilidade, força e/ou violência, mas ao mesmo tempo opera um deslocamento na construção do } \\
\text { masculino, tornando possível e aceitável para estes tipos de homens o fato de possúrem as axilas } \\
\text { sensíveis. }\end{array}$} \\
\hline \multicolumn{2}{|c|}{$\begin{array}{c}\text { Jogo pegado, é assim que tem que ser: estudo sobre a seriedade do lazer } \\
\text { numa rede de sociabilidade masculina }\end{array}$} \\
\hline Ano: 2011 & GTT: Recreação e lazer \\
\hline \multicolumn{2}{|c|}{ Autoria: Mauro Myskiw, Ariane Corrêa Pacheco e Maitê Venuto de Freitas } \\
\hline Temática: Sociabilidade masculina e lazer & Metodologia: Etnografia \\
\hline \multicolumn{2}{|l|}{ Noção de masculinidade: Guedes } \\
\hline \multicolumn{2}{|c|}{$\begin{array}{l}\text { Principais resultados: O "jogo pegado" compreende um modo de afirmação de um tipo de masculinidade. } \\
\text { Participar, com seriedade, de um "jogo pegado" é reafirmar o pertencimento e o reconhecimento na rede } \\
\text { de sociabilidade masculina }\end{array}$} \\
\hline \multicolumn{2}{|c|}{$\begin{array}{l}\text { As vivências de lazer dos homossexuais masculinos que vivem com o } \\
\text { HIV/AIDS: alguns apontamentos históricos e sociais }\end{array}$} \\
\hline Ano: 2011 & GTT: Movimentos sociais \\
\hline
\end{tabular}




\begin{tabular}{|c|c|}
\hline $\begin{array}{l}\text { Temática: Homens homossexuais com HIV e } \\
\text { lazer }\end{array}$ & $\begin{array}{l}\text { Metodologia: Pesquisa intervenção com observações e } \\
\text { entrevistas semiestruturadas }\end{array}$ \\
\hline \multicolumn{2}{|l|}{ Noção de masculinidade: Seffner; Silva; Sales } \\
\hline \multicolumn{2}{|c|}{$\begin{array}{l}\text { Principais resultados: A discriminação e a estigmatização compromete a vivência do lazer dos sujeitos. A } \\
\text { auto e heterodiscriminação dificultam o acesso aos espaços de lazer, limitando-os aos guetos e, até } \\
\text { mesmo, ao ambiente doméstico }\end{array}$} \\
\hline \multicolumn{2}{|c|}{ Limites e preconceitos em modalidades hegemonicamente masculinas: o caso do boxe feminino } \\
\hline Ano: 2013 & GTT: Inclusão e diferenças \\
\hline \multicolumn{2}{|c|}{ Autoria: Berta Leni Costa Cardoso, Carmen Jansen de Cárdenas e Tânia Mara Vieira Sampaio } \\
\hline Temática: Gênero e boxe feminino & Metodologia: Entrevistas semiestruturadas \\
\hline \multicolumn{2}{|c|}{ Noção de masculinidade: Goellner; Confortin; Simões, Conceição e Nery; Simões, Cortez e Conceição } \\
\hline \multicolumn{2}{|c|}{$\begin{array}{l}\text { Principais resultados: As atletas entrevistadas afirmaram que sofrem ou sofreram algum tipo de preconceito } \\
\text { em sua trajetória de boxeadoras, num esporte tido como masculino }\end{array}$} \\
\hline \multicolumn{2}{|c|}{$\begin{array}{c}\text { Em defesa da honra: masculinidades e práticas corporais de hipertrofia numa academia de Porto } \\
\text { Alegre }\end{array}$} \\
\hline Ano: 2013 & GTT: Corpo e cultura \\
\hline \multicolumn{2}{|l|}{ Autoria: Humberto Luís Cesaro } \\
\hline Temática: Masculinidades e hipertrofia & Metodologia: Etnografia \\
\hline \multicolumn{2}{|l|}{ Noção de masculinidade: Chaves; Fraga } \\
\hline \multicolumn{2}{|c|}{$\begin{array}{l}\text { Principais resultados: Mesmo demonstrando interesse em aderir às práticas de cuidados corporais, o } \\
\text { grupo de homens que frequenta a academia se enquadrava nos modelos hegemônicos naquele espaço }\end{array}$} \\
\hline \multicolumn{2}{|c|}{ Feminilidades e masculinidades: os entrelugares na e da es cola } \\
\hline Ano: 2013 & GTT: Escola \\
\hline \multicolumn{2}{|c|}{ Autoria: LisianeGoettems e Maria Simone VioneSchwengber } \\
\hline $\begin{array}{l}\text { Temática: Gênero, sexualidade e Educação } \\
\text { Física escolar }\end{array}$ & Metodologia: Etnografia \\
\hline \multicolumn{2}{|l|}{ Noção de masculinidade: Louro; Damo; Connell } \\
\hline \multirow{2}{*}{\multicolumn{2}{|c|}{$\begin{array}{l}\text { Principais resultados: Conflitos de gênero na escola quando meninas e meninos não se aproximam de } \\
\text { práticas generificadas na escola }\end{array}$}} \\
\hline & \\
\hline Ano: 2015 & GTT: Gênero \\
\hline \multicolumn{2}{|l|}{ Autoria: Sebastião Carlos Almeida } \\
\hline Temática: Masculinidades e artes marciais & Metodologia: Pesquisa bibliográfica \\
\hline \multicolumn{2}{|c|}{ Noção de masculinidade: Connell e Messerschimidt; Dunning e Maguire; Anderson; Mosse; Nye } \\
\hline \multicolumn{2}{|c|}{$\begin{array}{l}\text { Principais resultados: As artes marciais adquirem credibilidade e funcionam para reforçar masculinidades } \\
\text { hegemônicas }\end{array}$} \\
\hline \multicolumn{2}{|c|}{$\begin{array}{l}\text { Estigmas do corpo, gênero e sexualidade no esporte: voleibol enquanto espaço da mulher e da } \\
\text { "bicha" }\end{array}$} \\
\hline Ano: 2015 & GTT: Gênero \\
\hline \multicolumn{2}{|l|}{ Autoria: Paula Nunes Chaves } \\
\hline $\begin{array}{l}\text { Temática: Masculinidades homossexuais e } \\
\text { voleibol }\end{array}$ & Metodologia: Entrevistas semiestruturadas \\
\hline \multicolumn{2}{|c|}{ Noção de masculinidade: Costa; Dunning e Maguire } \\
\hline $\begin{array}{l}\text { Principais resultados: Os atletas entrevista } \\
\text { partindo de técnicos, adversários, torcida e fa }\end{array}$ & $\begin{array}{l}\text { los apontam vivencias discriminatórias nas competições, } \\
\text { nília }\end{array}$ \\
\hline \multicolumn{2}{|c|}{ Mulheres torcedoras de futebol: questionando as masculinidades circulantes nas arquibancadas } \\
\hline Ano: 2017 & GTT: Gênero \\
\hline & \\
\hline
\end{tabular}




\begin{tabular}{|c|c|}
\hline Temática: Mulheres e torcidas de futebol & Metodologia: Entrevistas semiestruturadas \\
\hline \multicolumn{2}{|c|}{ Noção de masculinidade: Goellner; Dunning; Elias; Monteiro } \\
\hline \multicolumn{2}{|c|}{$\begin{array}{l}\text { Principais resultados: As torcedoras relatam as interdições que vivenciam nas torcidas, suas reivindicações } \\
\text { coletivas e a decisão de se organizar, a fim de garantir "igualdade" e "empoderamento" nas arquibancadas }\end{array}$} \\
\hline \multicolumn{2}{|c|}{$\begin{array}{c}\text { Performances de masculinidades no contexto do voleibol: narrativas em perspectiva } \\
\text { interseccional }\end{array}$} \\
\hline Ano: 2017 & GTT: Gênero \\
\hline \multicolumn{2}{|l|}{ Autoria: Leandro Teofilo de Brito } \\
\hline $\begin{array}{l}\text { Temática: Masculinidades homossexuais e } \\
\text { voleibol }\end{array}$ & Metodologia: Entrevista narrativa dialógica \\
\hline \multicolumn{2}{|l|}{ Noção de masculinidade: Butler; Bilge } \\
\hline \multicolumn{2}{|c|}{$\begin{array}{l}\text { Principais resultados: Masculinidade interseccionada às categorias idade, orientação sexual, deficiência e } \\
\text { classe social nas vivências do jovem atleta entrevistado }\end{array}$} \\
\hline \multicolumn{2}{|c|}{$\begin{array}{c}\text { Por onde andam as meninas? Educação Física, esportes } \\
\text { e dominação masculina nos jogos do IFCE } \\
\end{array}$} \\
\hline Ano: 2019 & GTT: Epistemologia \\
\hline \multicolumn{2}{|l|}{ Autoria: Daniel Pinto Gomes } \\
\hline $\begin{array}{lll}\text { Temática: Dominação } & \text { masculina } & \mathrm{e} \\
\text { competição esportiva }\end{array}$ & Metodologia: Etnografia \\
\hline \multicolumn{2}{|l|}{ Noção de masculinidade: Bourdieu } \\
\hline \multicolumn{2}{|c|}{$\begin{array}{l}\text { Principais resultados: Baixa participação de meninas e mulheres nos jogos como reflexo dos processos } \\
\text { naturalizados da dominação masculina }\end{array}$} \\
\hline \multicolumn{2}{|c|}{ Noções de masculinidade(s) no ensino supe rior de Educação Física } \\
\hline Ano: 2019 & GTT: Gênero \\
\hline \multicolumn{2}{|c|}{ Autoria: Rafael Marques Garcia e Erik Giuseppe Barbosa Pereira } \\
\hline $\begin{array}{l}\text { Temática: Masculinidades e formação inicial } \\
\text { de professores/as }\end{array}$ & Metodologia: Etnografia \\
\hline \multicolumn{2}{|c|}{ Noção de masculinidade: Brito e Leite; Oliveira; Pereira; Seffner } \\
\hline \multirow{2}{*}{\multicolumn{2}{|c|}{$\begin{array}{c}\text { Principais resultados: Princípios heteronormativos estimulam a exacerbação d } \\
\text { tradicional, contendo elementos ditos hegemônicos e que menosprezam as demais } \mathrm{n} \\
\text { "Os meninos falam que ela é homem" - enunciações } \\
\text { normativas de gênero na Educação Física }\end{array}$}} \\
\hline & \\
\hline Ano: 2019 & GTT: Gênero \\
\hline \multicolumn{2}{|c|}{ Autoria: Carla Chagas Ramalho, Leandro Teofilo de Brito e José Jairo Vieira } \\
\hline $\begin{array}{l}\text { Temática: Gênero, sexualidade e Educação } \\
\text { Física escolar }\end{array}$ & Metodologia: Entrevista não estruturada \\
\hline \multicolumn{2}{|l|}{ Noção de masculinidade: Scott; Butler; Goellner } \\
\hline \multirow{2}{*}{\multicolumn{2}{|c|}{$\begin{array}{l}\text { Principais resultados: As diferenciações sobre as representatividades de gênero são corroboradas durante } \\
\text { as aulas de Educação Física, através das cobranças e expectativas das expressões corporais } \\
\text { O repúdio à Coligay }\end{array}$}} \\
\hline & \\
\hline Ano: 2019 & GTT: Gênero \\
\hline \multicolumn{2}{|c|}{ Autoria: Luiza Aguiar dos Anjos e Silvana VilodreGoellner } \\
\hline $\begin{array}{l}\text { Temática: Homossexualidade masculina e } \\
\text { torcidas de futebol }\end{array}$ & Metodologia: História oral \\
\hline \multicolumn{2}{|c|}{ Noção de masculinidade: Bandeira; McComack e Anderson; Cashmore e Cleland } \\
\hline Principais resultados: As autoras constatam c & $\begin{array}{l}\text { que a rejeição à torcida Coligay não ocorreu em todos os } \\
\text { a jocosidade foi e continua recorrente a uma torcida gay }\end{array}$ \\
\hline
\end{tabular}




\begin{tabular}{|l|l|}
\hline $\begin{array}{l}\text { Da masculinidade hegemônica à masculinidade queer/cuir: debatendo performatizações } \\
\text { emergentes do masculino no esporte brasileiro }\end{array}$ \\
\hline Ano: 2019 & GTT: Gênero \\
\hline Autoria: Leandro Teofilo de Brito \\
\hline $\begin{array}{l}\text { Temática: Masculinidades no esporte } \\
\text { brasileiro }\end{array}$ & Metodologia: Ensaio \\
\hline Noção de masculinidade: Connell; Derrida; Butler; Laclau e Mouffe \\
\hline $\begin{array}{l}\text { Principais resultados: A emergência de masculinidades alternativas no esporte brasileiro é significada por } \\
\text { disputas de sentidos }\end{array}$ \\
\hline
\end{tabular}

Fonte: Anais CBCE

Entre os 21 trabalhos selecionados para o mapeamento, localizamos o seguinte quantitativo entre os encontros: 1 trabalho em 2005, 1 trabalho em 2007, 2 trabalhos em 2009, 5 trabalhos em 2011, 3 trabalhos em 2013, 2 trabalhos em 2015, 2 trabalhos em 2017 e 5 trabalhos em 2019. Discutindo esse quantitativo, tivemos um crescimento do número de trabalhos de 2005 para 2011, uma queda entre os encontros de 2013 e 2017 e novamente um crescimento no evento de 2019. Como já mencionamos, o debate sobre a masculinidade tóxica é uma pauta contemporânea na sociedade, que tem sido visibilizada tanto pelos movimentos sociais como por pesquisadores/as dos estudos de gênero, que colocam em discussão as formas culturais mais tradicionais de "ser homem" como maléficas para os sujeitos (CASTRO, 2018). Neste sentido, o crescimento de trabalhos no encontro de 2019, após uma queda nos três eventos anteriores, pode ser significado pela ampliação desta discussão na sociedade, que, certamente, atravessa o contexto das práticas corporais e esportivas.

Estes trabalhos foram direcionados aos seguintes GTTs: Recreação e lazer, Movimentos sociais, Inclusão e diferenças e Epistemologia com 1 trabalho em cada; Comunicação e mídia e Escola com um total de 2 trabalhos em cada; Corpo e cultura com um total de 5 trabalhos; e Gênero com um total de 8 trabalhos. Assim, podemos afirmar que a criação do GTT Gênero, além de concentrar a discussão sobre a categoria masculinidade num espaço específico no evento, recebeu 8 trabalhos sobre a temática nos primeiros três eventos desde sua existência, propiciando que o debate pudesse também ser mais desenvolvido em um curto espaço de tempo.

Sobre as temáticas, classificamos os trabalhos em nas seguintes subtemáticas: gênero e desenhos animados (CARRAZZONI; WENETZ, 2005); masculinidades e mídia (KNIJNIK et al., 2007; GODOI, 2009; MILITO; MARTINS, 2011); gênero e iniciação esportiva (OLIVEIRA; SILVA, 2011); sociabilidade masculina e lazer (MYSKIW; PACHECO; FREITAS, 2011); homens homossexuais com HIV e lazer (SALES, 2011); gênero e boxe feminino (CARDOSO; CÁRDENAS; SAMPAIO, 2013); masculinidades e hipertrofia (CESARO, 2013); masculinidades e artes marciais (ALMEIDA, 2015); masculinidades homossexuais e voleibol (CHAVES, 2015; BRITO, 2017); mulheres e torcidas de futebol (MARTINS, 2017); dominação masculina e competição esportiva (GOMES, 2019); masculinidades e 
formação inicial de professores/as (GARCIA; PEREIRA, 2019); gênero, sexualidade e Educação Física escolar (DORNELLES, 2009; WENETZ; DORNELLES, 2011; GOETTEMS; SCHWENGBER, 2013; RAMALHO; BRITO; VIEIRA, 2019); homossexualidade masculina e torcidas de futebol (ANJOS; GOELLNER, 2019); e masculinidades no esporte brasileiro (BRITO, 2019).

Discutindo a articulação destes temas com as noções teóricas que fundamentaram os textos e seus principais resultados, problematizamos os trabalhos que trouxeram o aspecto relacional do gênero para discussão sobre a categoria masculinidade. Os trabalhos de Carrazzoni e Wenetz (2005),Dornelles (2009), Oliveira e Silva (2011), Cardoso, Cárdenas e Sampaio (2013), Goettems e Schwengber (2013), Martins (2017) e Ramalho, Brito e Vieira (2019) fizeram uso do clássico texto Gênero: uma categoria útil de análise histórica da teórica feminista Joan Scott e/ou suas leituras/apropriações por Guacira Louro, Silvana Goellner, entre outras/os autoras/es para discutir os aspectos relacionais do masculino e feminino em suas pesquisas. Nesta perspectiva, o termo gênero sugere que qualquer informação sobre as mulheres implica necessariamente informações também sobre os homens e tal posição refuta a ideia essencialista de que as experiências de homens e mulheres tenha muito pouco ou nenhuma proximidade entre si. Neste sentido, reconhecemos a potencialidade do aspecto relacional do gênero, pois essa perspectiva "trata-se de uma forma de se referir às origens exclusivamente sociais das identidades subjetivas de homens e mulheres" (SCOTT, 1995, p. 75). As proposições de Joan Scott abriram caminhos para o desenvolvimento dos estudos sobre as masculinidades na literatura sobre gênero por uma matriz feminista, pois "quando as teorias feministas forjam o conceito de 'gênero' nessa dimensão relacional, que os estudos sobre homens e masculinidades como objeto de análises ganham maior ênfase" (MEDRADO; LYRA, 2008, p. 820). Cabe colocar que a perspectiva relacional também esteve presente em outros trabalhos selecionados no mapeamento, mas com força menor do que estes em que destacamos para problematização.

Entre estes trabalhos mencionados, os/as autores/as propuseram interpretações que trouxeram a categoria masculinidade imbricada à feminilidade, tomando como objeto de análise vivências específicas de mulheres e conjuntas entre homens e mulheres no contexto das práticas corporais e esportivas. Como exemplo, destacamos o trabalho de Cardoso, Cárdenas e Sampaio (2013), que abordou as experiências de mulheres lutadoras de boxe, considerando este um esporte tido socialmente como masculino; e os trabalhos de Dornelles (2009), que discutiu a questão da separação de meninos e meninas nas aulas de Educação Física escolar, e Ramalho, Brito e Vieira (2019), que problematizou as cobranças e expectativas associadas a meninos e meninas nas aulas mistas de Educação Física escolar.

No mapeamento, três trabalhos trouxeram como tema masculinidades e mídia. As publicações de Knijnik et al. (2007), Godoi (2009) e Milito e Martins (2011) abordaram, respectivamente, discursos de radialistas sobre as masculinidades no esporte, a construção da categoria metrossexual em matérias de 
revistas e uma propaganda de desodorante masculino. Neste contexto, os sentidos afirmados pela masculinidade hegemônica estiveram presentes no trabalho de Knijnik et al. (2007), quando os autores denunciam os discursos de radialistas esportivos que enfatizam um modo único de "ser homem" em comentários sobre o futebol. Na mesma direção, o trabalho de Godoy (2009) aponta que apesar do homem metrossexual ser tido como uma masculinidade alternativa na sociedade, sentidos da masculinidade hegemônica ainda se fazem presentes para legitimar a lógica capitalista de consumo e validar ou refutar os corpos masculinos nas normas. Já o trabalho de Milito e Martins (2011) trouxe deslocamentos importantes sobre as masculinidades na análise de uma propaganda de desodorante para homens, que enfatiza um determinado produto para axilas sensíveis. Nas imagens, variados tipos de homens - todos enquadrados nos modelos da masculinidade hegemônica - possuem certa sensibilidade na região e mostram-se interessados em utilizarem o produto. Estes pesquisadores fundamentaram suas análises em autores/as localizados nos estudos culturais, tais como Stuart Hall e Kathryn Woodward, para discutir os deslocamentos produzidos sobre os sentidos do masculino. Os estudos culturais são um quadro teórico que possui uma heterogeneidade de perspectivas e influências disciplinares, mas que, consensualmente, concentram-se na análise da cultura, concebendo-a como um campo de luta em torno da significação social, no qual diferentes grupos sociais e em relações diferenciais de poder disputam a imposição de seus significados à sociedade mais ampla (SILVA, 2005).

As masculinidades homossexuais estiveram presentes em cinco trabalhos mapeados, que trouxeram como temas homens homossexuais soropositivos para o HIV e suas vivências de lazer (SALES, 2011), homens atletas do voleibol universitário que se identificavam como homossexuais (CHAVES, 2015), as experiências de um jovem atleta homossexual da base de voleibol e as opressões vivenciadas neste espaço (BRITO, 2017) e a histórica torcida gremista Coligay (ANJOS; GOELLNER, 2019). Já o trabalho de Brito (2019), trouxe a homossexualidade como uma categoria, mas não central em seu texto, e discutiu a emergência contemporânea de masculinidades alternativas no contexto do esporte brasileiro. Entre estes textos, a homofobia esteve enunciada nos dois trabalhos que abordaram o espaço do voleibol. Chaves (2015) apontou em sua pesquisa que os atletas homossexuais de voleibol entrevistados relataram situações de homofobia vivenciadas no espaço do esporte, por meio de discursos preconceituosos de treinadores e de atletas heterossexuais, familia e torcida. Além disso, o voleibol nestes discursos era tido como uma prática culturalmente voltada às mulheres, o que, para o senso comum, associava-se à homossexualidade masculina. No trabalho de Brito (2017), a categoria orientação sexual se mostrava como uma das opressões - integrada à classe social e à deficiência - narradas por um jovem atleta de base do voleibol, que, a pedido de seu treinador, precisava esconder o fato de ser homossexual e, sobretudo, um sujeito afeminado nos treinos e nos jogos. 
Para Borrillo (2010) a homofobia é a atitude de hostilidade, rejeição irracional e ódio contra pessoas que se identificam como homossexuais. Uma manifestação arbitrária que consiste em designar o outro como contrário, inferior ou anormal. $\mathrm{O}$ autor também pontua que a homofobia se coloca como guardiã das fronteiras sexuais (hetero/homo), como também do binarismo de gênero (masculino/feminino), segregando aqueles sujeitos que não se conformam a essa ordem. Rosa et al. (2019) chamam atenção para que o termo homofobia não seja utilizado em sentido fixo e fechado. Reconhecem como um termo direcionado a homens que se identificam como homossexuais, mas que outros sujeitos, identificados como heterossexuais e bissexuais, também podem vivenciar tal opressão, por não se enquadrarem nas normas do que se entende ser um homem heterossexual. Retomando os dados das pesquisas de Chaves (2015) e Brito (2017), o entendimento do voleibol como um esporte restrito para mulheres e sua equivocada associação à homossexualidade, assim como a negação de aspectos tidos como femininos na corporalidade de um homem atleta, reitera significações da homofobia no contexto mais amplo das práticas corporais e esportivas, já que a mesma "pode ser percebida nas piadas vulgares que ridicularizam o indivíduo afeminado" (BORRILLO, 2010, p. 16).

A teorização da masculinidade hegemônica fundamentou os trabalhos de Knijnik et al. (2007), Godoi (2009), Almeida (2015) e Brito (2019). Os trabalhos de Cardoso, Cárdenas e Sampaio (2013), Chaves (2015) e Garcia e Pereira (2019) utilizaram a expressão em sentido dicionarizado, sem remetê-la a alguma fundamentação teórica. Nos levantamentos de Brito e Leite (2017, 2019), que focalizaram publicações em periódicos, a teorização da masculinidade hegemônica em Kimmel (1998) e Connell (2003, 2016) esteve presente na maior parte dos artigos da área da Educação Física, mas nos trabalhos publicados no CONBRACE/CONICE vimos uma gama diversa e até mesmo dispersa de teorizações no debate sobre a masculinidade. Nestes trabalhos localizados com fundamentação na masculinidade hegemônica, constatamos uma ênfase grande na perspectiva da denúncia, que aponta o domínio da hegemonia do masculino no contexto das práticas corporais e esportivas, conforme os textos de Knijnik et al. (2007) e Almeida (2015). Já o texto de Brito (2019) realiza uma crítica a essa teorização ao apostar no uso das perspectivas pós-estruturalistas para o debate sobre as masculinidades na contemporaneidade. Outros trabalhos, como os de Dornelles (2009), Wenetz e Dornelles (2011), Oliveira e Silva (2011), Brito (2017), Garcia e Pereira (2019) e Ramalho, Brito e Vieira (2019) também buscaram aproximação com os estudos pós-estruturalistas em suas análises.

Compreende-se o pós-estruturalismo, em acordo com Williams (2013), como um conjunto de experimentos acerca de textos, ideias e conceitos que, com grande influência do campo da filosofia, mostram os limites do estruturalismo, buscando pensar as estruturas como descentradas e sem um centro de necessidade que as conforme e as estabilize em um sentido fixo e unívoco. O pós-estruturalismo dá significado à perspectiva da diferença, entendida como "variações abertas (que são chamadas, às vezes de 
processos de diferenciação, e, muitas vezes, diferenças puras). Esses efeitos são transformações, mudanças, reavaliações" (WILLIAMS, 2013, p. 16-17). Assim, pensar os estudos sobre masculinidades pelas perspectivas pós-estruturalistas nos remete a reconhecer uma multiplicidade de significações e identificações para o masculino, não restringindo a pesquisa acadêmica apenas ao campo da denúncia, mas sim em buscar alternativas e olhares mais amplos e complexos para o que está tido como estabelecido.

Neste sentido, quatro trabalhos do encontro de 2019 trouxeram a noção de heteronormatividade para a discussão sobre as masculinidades (GARCIA; PEREIRA, 2019; RAMALHO; BRITO; VIEIRA, 2019) e entre esses textos, dois acoplaram o prefixo cis ao termo (ANJOS; GOELLNER, 2019; BRITO, 2019). A noção de heteronormatividade diz respeito à produção e reiteração compulsória da norma heterossexual atrelada à imposição do binarismo de gênero (LOURO, 2009). A inserção do prefixo cis à noção, diz respeito a identificação cisgênero - pessoas que identificam-se com o gênero que lhes foi atribuído no momento do nascimento -, que é um esforço conceitual de se pensar o termo cisheteronormatividade como forma de discutir as normas político-sociais, que impõem práticas e códigos cisgêneros e heterossexuais a todas as pessoas (JARDIM, 2020). Concordamos com Louro (2009, p. 91), quando a autora afirma que "o processo de heteronormatividade parece ser exercido de modo mais intenso ou mais visível em relação ao gênero masculino".

Por fim, as metodologias dos trabalhos mapeados classificaram-se em: análise de artefatos culturais (1 trabalho), análise do discurso (1 trabalho), análise de documentos (1 trabalho), histórias de vida (2 trabalhos), análise de imagens (1 trabalho), pesquisa intervenção com observações e entrevistas semiestruturadas (1 trabalho), pesquisa bibliográfica (1 trabalho), ensaio (1 trabalho), entrevista não estruturada (1 trabalho), entrevista narrativa dialógica (1 trabalho), entrevistas semiestruturadas (5 trabalhos) e etnografia (5 trabalhos). As entrevistas, em seus diversos formatos, configuraram-se como os caminhos mais escolhidos para a discussão das masculinidades nas práticas corporais e esportivas e, logo em seguida, vem a etnografia. De uma maneira geral, as metodologias estiveram condizentes com os objetivos elencados nos trabalhos e também não houve nenhuma metodologia que se mostrasse alternativa ou inovadora para este campo de estudos, conforme as proposições de Meyer e Paraíso (2014), que apostam na bricolagem, montagem, remontagem, construção e reconstrução de métodos em articulação aos fundamentos teóricos utilizados para os modos de fazer pesquisa com a diferença.

\section{CONCLUSÕES}


Buscamos neste estudo, configurado como um levantamento bibliográfico, mapear e problematizar as publicações no CONBRACE/CONICE sobre a categoria masculinidade nos últimos quinze anos. Como uma subárea dentro dos estudos de gênero, a focalização da masculinidade como categoria na pesquisa acadêmica da área de Educação Física mostrou-se um campo ainda incipiente e que carece de maiores desenvolvimentos por partes de pesquisadores/as da temática. Neste contexto, a própria prevalência nas práticas corporais e esportivas de uma masculinidade hegemônica ou de outras expressões que denotavam uma dominação do masculino, preponderou nos trabalhos problematizados, visibilizando bem pouco os processos de resistência de masculinidades outras nestes espaços, o que vemos como uma lacuna a ser preenchida pelos futuros trabalhos.

Deste modo, pesquisas que visibilizem homens que se dedicam a práticas corporais e esportivas culturalmente reconhecidas como femininas, como as variadas modalidades de dança e ginástica, além do nado artístico - esporte que, recentemente, modificou suas regras e deixou de ser exclusivamente praticado por mulheres - podem ser focalizações potentes das pesquisas. Outros exemplos que destacamos, seria de meninos e jovens que resistem às regulações sociais impostas historicamente para as masculinidades nas aulas de Educação Física escolar, o recente surgimento de campeonatos e torneios de futebol e voleibol para homens que não se identificam como heterossexuais, a presença das transmasculinidades nos espaços de práticas corporais e esportivas, como também das expressões das masculinidades em corpos de mulheres, entre tantos outros temas podem ser focalizações produtivas e importantes para as futuras pesquisas.

Para isso, as fundamentações teóricas também podem ser ampliadas. Como vimos, as perspectivas pós-estruturalistas começaram a se fazer presentes nos trabalhos, sobretudo nas publicações mais recentes, complexificando as análises e trazendo novos olhares para as rupturas e os deslocamentos produzidos pelas masculinidades nas práticas corporais e esportivas. Outras teorizações como a interseccionalidade, a decolonialidade e a pós-colonialidade podem ser interlocuções teóricas que permitem que a categoria masculinidade possa ser interpretada por atravessamentos de raça e classe, entre outros marcadores da diferença, contribuindo com novas interpretações para os processos de opressão, dominação, agência e ressignificação nas relações sociais articuladas ao corpo, às atividades físicas e aos esportes. Finalizamos este texto na expectativa de que nosso estudo possa ter contribuído como uma revisão importante do que foi produzido até então sobre o tema na área da Educação Física, pelo recorte da produção no CONBRACE/CONICE, e no estímulo de que novos e atuais pesquisadores/as possam se dedicar à ampliação e desenvolvimento dos estudos sobre masculinidades via práticas corporais e esportivas. 


\section{REFERÊNCIAS}

ALMEIDA, Sebastião Carlos. Arte marcial e masculinidades: relações modernas para culturas tradicionais. In: XIX CONGRESSO BRASILEIRO DE CIÊNCIAS DO ESPORTE, 19., VI CONGRESSO INTERNACIONAL DE CIÊNCIAS DO ESPORTE, 6., 2015, Vitória. Anais... Vitória, CBCE, 2015. Disponível em: https:/bit.ly/3hONRKy. Acesso em: 31 de jul. 2020.

ANJOS, Luiza Aguar dos; GOELLNER, Silvana Vilodre. O repúdio à Coligay. In: XXI CONGRESSO BRASILEIRO DE CIÊNCIAS DO ESPORTE, 21., VIII CONGRESSO INTERNACIONAL DE CIÊNCIAS DO ESPORTE, 8., 2019, Natal. Anais... Natal, CBCE, 2019. Disponível em:https:/bit.ly/31hDR5T. Acesso em: 31 de jul. 2020.

BORRILLO, Daniel. Homofobia: história e crítica de um preconceito. Belo Horizonte: Autêntica Editora, 2010.

BRITO, Leandro Teofilo de. Da masculinidade hegemônica à masculinidade queer/cuir: debatendo performatizações emergentes do masculino no esporte brasileiro. In: XXI CONGRESSO BRASILEIRO DE CIÊNCIAS DO ESPORTE, 21., VIII CONGRESSO INTERNACIONAL DE CIÊNCIAS DO ESPORTE, 8., 2019, Natal. Anais... Natal, CBCE, 2019. Disponível em: https://bit.ly/2ExyLe4. Acesso em: 31 de jul. 2020.

BRITO, Leandro Teofilo de. Performances de masculinidades no contexto do voleibol: narrativas em perspectiva interseccional. In: XX CONGRESSO BRASILEIRO DE CIÊNCIAS DO ESPORTE, 20., VII CONGRESSO INTERNACIONAL DE CIÊNCIAS DO ESPORTE, 7., 2017, Goiânia. Anais... Goiânia, CBCE, 2017. Disponível em:https://bit.ly/2EuElxN. Acesso em: 31 de jul. 2020.

BRITO, Leandro Teofilo de; LEITE, Miriam Soares. Pesquisar a masculinidade na Educação: sobre o potencial performativo do texto acadêmico. In: 39a REUNIÃO NACIONAL DA ANPED, 39., 2019, Niterói. Anais... Niterói, ANPED, 2019.Disponível em: https//bit.ly/3jePhz3. Acesso em: 29 de set. 2020.

BRITO, Leandro Teofilo de; LEITE, Miriam Soares. Sobre masculinidades na Educação Física escolar: questões teóricas, horizontes políticos. Práxis Educativa, Ponta Grossa, v. 12, n. 2, p. 481-500, maio/ago. 2017.Disponível em: https:/bit.ly/34754da. Acesso em: 29 de set. 2020.

BRITO, Leandro Teofilo de; SANTOS, Mônica Pereira dos. Masculinidades na Educação Física escolar: um estudo sobre os processos de inclusão/exclusão. Revista Brasileira de Educação Física e Esporte, São Paulo, v. 27, n. 2, p. 235-246, abr./jun. 2013. Disponível em: https://bit.ly/2CXoB5Z. Acesso em: 28 de jul. 2020.

CARDOSO, Berta Leni Costa; CÁRDENAS, Carmem Jansen de; SAMPAIO, Tânia Mara Vieira. Limites e preconceitos em modalidades hegemonicamente masculinas: o caso do boxe feminino. In: XVIII CONGRESSO BRASILEIRO DE CIÊNCIAS DO ESPORTE, 18., V CONGRESSO

INTERNACIONAL DE CIÊNCIAS DO ESPORTE, 5., 2013, Brasília. Anais... Brasília, CBCE, 2013. Disponível em: https://bit.ly/315qtSv. Acesso em: 31 de jul. 2020.

CASTRO, Susana de. O papel das escolas no combate às masculinidades tóxicas. Revista Aprender, Vitória da Conquista, n. 20, p. 75-82, jul./dez. 2018. Disponível em: https://bit.ly/3jOkiuE. Acesso em: 28 de jul. 2020. 
CESARO, Humberto Luís Cesaro. Em defesa da honra: masculinidades e práticas corporais de hipertrofia numa academia de Porto Alegre. In: XVIII CONGRESSO BRASILEIRO DE CIÊNCIAS DO ESPORTE, 18., V CONGRESSO INTERNACIONAL DE CIÊNCIAS DO ESPORTE, 5., 2013, Brasília. Anais... Brasília, CBCE, 2013. Disponível em: https:/bit.ly/33djSIc. Acesso em: 31 de jul. 2020.

CHAVES, Paula Nunes. Estigmas do corpo, gênero e sexualidade no esporte: voleibol enquanto espaço da mulher e da "bicha". In: XIX CONGRESSO BRASILEIRO DE CIÊNCIAS DO ESPORTE, 19., VI CONGRESSO INTERNACIONAL DE CIÊNCIAS DO ESPORTE, 6., 2015, Vitória. Anais... Vitória, CBCE, 2015. Disponível em: https:/bit.ly/3 giMGCV. Acesso em: 31 de jul. 2020.

CONNELL, Raewyn. Gênero em termos reais. São Paulo: nVersos, 2016.

CONNELL, Raewyn. Masculinidades. México: UNAM-PUEG, 2003.

CARRAZZONI, Daniel Krás; WENETZ, Ileana. Os discursos corporais produzidos pelosdesenhos animados "Popeye" e "Liga da Justiça". In: XIV CONGRESSO BRASILEIRO DE CIÊNCIAS DO ESPORTE, 14., I CONGRESSO INTERNACIONAL DE CIÊNCIAS DO ESPORTE, 1., 2005, Porto Alegre. Anais... Porto Alegre, CBCE, 2005. Disponível em: https://bit.ly/2BMQ0XX. Acesso em: $31 \mathrm{de}$ jul. 2020.

DORNELLES, Priscila Gomes. A separação de meninos e meninas na educação fisica escolar: marcas de gênero. In: XVI CONGRESSO BRASILEIRO DE CIÊNCIAS DO ESPORTE, 16., III CONGRESSO INTERNACIONAL DE CIÊNCIAS DO ESPORTE, 3., 2009, Salvador. Anais... Salvador, CBCE, 2009. Disponível em: https://bit.ly/2Xt41Ax. Acesso em: 31 de jul. 2020.

DUNNING, Eric. O esporte como um domínio masculino: observações sobre as fontes sociais da identidade masculina e suas transformações. In: REIS, Heloisa Helena Baldy dos (Org.). Sociologia do esporte e os processos civilizatórios. São Paulo: Anablume, 2014, p. 233-254.

GARCIA, Rafael Marques; PEREIRA, Erik Giuseppe Barbosa. Noções de masculinidade(s) no ensino superior de Educação Física. In: XXI CONGRESSO BRASILEIRO DE CIÊNCIAS DO ESPORTE, 21., VIII CONGRESSO INTERNACIONAL DE CIÊNCIAS DO ESPORTE, 8., 2019, Natal. Anais... Natal, CBCE, 2019. Disponível em: https://bit.ly/3fkijut. Acesso em: 31 de jul. 2020.

GODOI, Marcos Roberto. Corpo, cultura e masculinidade: os discursos sobre um "novo" tipo de homem na mídia impressa, o "metrossexual". In: XVI CONGRESSO BRASILEIRO DE CIÊNCIAS DO ESPORTE, 16., III CONGRESSO INTERNACIONAL DE CIÊNCIAS DO ESPORTE, 3., 2009, Salvador. Anais... Salvador, CBCE, 2009. Disponível em: https://bit.ly/3gllVO0. Acesso em: 31 de jul. 2020.

GOELLNER, Silvana Vilodre. A contribuição dos estudos de gênero e feministas para o campo acadêmico-profissional da Educação Física. In: DORNELLES, Priscila Gomes; WENETZ, Ileana; SCHWENGEBER, Maria Simone Vione (Orgs.). Educação Física e Gênero: desafios educacionais. Ijuí: Unijuí, 2013, p. 23-44.

GOETTEMS, Lisiane; SCHWENGBER, Maria Simone Vione. Feminilidades e masculinidades: os entrelugares na e da escola. In: XVIII CONGRESSO BRASILEIRO DE CIÊNCIAS DO ESPORTE, 18., V CONGRESSO INTERNACIONAL DE CIÊNCIAS DO ESPORTE, 5., 2013, Brasília. Anais... Brasília, CBCE, 2013. Disponível em: https://bit.ly/3jZnnYU. Acesso em: 31 de jul. 2020. 
GOMES, Daniel Pinto. Por onde andam as meninas? Educação Física, esportes e dominação masculina nos jogos do IFCE. In: XXI CONGRESSO BRASILEIRO DE CIÊNCIAS DO ESPORTE, 21., VIII CONGRESSO INTERNACIONAL DE CIÊNCIAS DO ESPORTE, 8., 2019, Natal. Anais... Natal, CBCE, 2019. Disponível em: https:/bit.ly/3k0XxDC. Acesso em: 31 de jul. 2020.

JARDIM, Juliana Gomes. Cis-heteronormatividade, MMA, Educação Física e sociedade.

Movimentalidade, Bauru, abr. 2020. Disponível em: https:/bit.ly/37w1yKq. Acesso em: 6 de ago. 2020.

KIMMEL, Michael S. A produção simultânea de masculinidades hegemônicas e subalternas. Horizontes Antropológicos, Porto Alegre, v. 4, n. 9, p. 103-117, out. 1998. Disponível em: https://bit.ly/2DsN3fw. Acesso em: 31 de jul. 2020.

KNIJNIK, Jorge Dorfman; SILVA, Eduardo Vinicius Mota; SOUZA, Janísio Xavier de; NETO, Antenor Magno da Silva; BERTO, Judá Eckert; FERREIRA JÚNIOR, Neilton; DELFINO, Paulo César Falcão; SILVA, Adriano Cruz da; SANTOS, Cristina Vieira dos. De menino a homem: a mídia e a construção de masculinidades esportivas. In: XV CONGRESSO BRASILEIRO DE CIÊNCIAS DO ESPORTE, 15., II CONGRESSO INTERNACIONAL DE CIÊNCIAS DO ESPORTE, 2., 2007, Pernambuco. Anais... Pernambuco, CBCE, 2007. Disponível em: https://bit.ly/2XfAsDn. Acesso em: 31 de jul. 2020.

LOURO, Guacira. Heteronormatividade e homofobia. In: JUNQUEIRA, Rogério (Org.). Diversidade Sexual na Educação: problematizações sobre a homofobia nas escolas. Brasília: Ministério da Educação, Secretaria de Educação Continuada, Alfabetização e Diversidade, UNESCO, 2009, p. 85-93.

MARTINS, Mariana Zuaneti. Mulheres torcedoras de futebol: questionando as masculinidades circulantes nas arquibancadas. In: XX CONGRESSO BRASILEIRO DE CIÊNCIAS DO ESPORTE, 20., VII CONGRESSO INTERNACIONAL DE CIÊNCIAS DO ESPORTE, 7., 2017, Goiânia. Anais... Goiânia, CBCE, 2017. Disponível em: https://bit.ly/3jVHLtM. Acesso em: 31 de jul. 2020.

MEDRADO, Benedito; LYRA, Jorge. Por uma matriz feminista de gênero para os estudos sobre homens e masculinidades. Revista Estudos Feministas, Florianópolis, v. 16, n. 3, set./dez. 2008. Disponível em: https//bit.ly/3jRP7hN. Acesso em: 28 de jul. 2020.

MEYER, Dagmar; PARAÍSO, Marlucy. Metodologias de pesquisas pós-críticas ou sobre como fazemos nossas investigações. In MEYER, Dagmar; PARAÍSO, Marlucy (Orgs.). Metodologias de pesquisas pós-críticas em Educação. $2^{\mathrm{a}}$ ed. Belo Horizonte: Mazza Edições, p. 17-24.

MILITO, Caio AnawateKuri; MARTINS, Carlos José. Modelos de identidades masculinas na propaganda de desodorante: novos deslocamentos. In: XVII CONGRESSO BRASILEIRO DE CIÊNCIAS DO ESPORTE, 17., IV CONGRESSO INTERNACIONAL DE CIÊNCIAS DO ESPORTE, 4., 2011, Porto Alegre. Anais... Porto Alegre, CBCE, 2011. Disponível em: https:/bit.ly/3gvfHvn. Acesso em: 31 de jul. 2020.

MORAES E SILVA, Marcelo; CESAR, Maria Rita de Assis. As masculinidades produzidas nas aulas de educação física: percepções docentes. Motrivivência, Florianópolis, n.39, p. 101-112, dez. 2012. Disponível em: https://bit.ly/3g7QqXD . Acesso em: 28 de jul. 2020.

MYSKIW, Mauro; PACHECO, Ariane Corrêa; FREITAS, Maitê Venuto de. Jogo pegado, é assim que tem que ser: estudo sobre a seriedade do lazer numa rede de sociabilidade masculina. In: XVII CONGRESSO BRASILEIRO DE CIÊNCIAS DO ESPORTE, 17., IV CONGRESSO 
INTERNACIONAL DE CIÊNCIAS DO ESPORTE, 4., 2011, Porto Alegre. Anais... Porto Alegre, CBCE, 2011. Disponível em: https://bit.ly/2EETT2b. Acesso em: 31 de jul. 2020.

OLIVEIRA, Victor José Machado; SILVA, Erineusa Maria da. Histórias de vida e o processo de subjetivação das experiências de adolescentes aprendizes com um esporte masculinizado. In: XVII CONGRESSO BRASILEIRO DE CIÊNCIAS DO ESPORTE, 17., IV CONGRESSO

INTERNACIONAL DE CIÊNCIAS DO ESPORTE, 4., 2011, Porto Alegre. Anais... Porto Alegre, CBCE, 2011. Disponível em: https://bit.ly/2D70aTU. Acesso em: 31 de jul. 2020.

RAMALHO, Carla Chagas; BRITO, Leandro Teofilo de; VIEIRA, José Jairo. “Os meninos falam que ela é homem” - enunciações normativas de gênero na Educação Física. In: XXI CONGRESSO BRASILEIRO DE CIÊNCIAS DO ESPORTE, 21., VIII CONGRESSO INTERNACIONAL DE CIÊNCIAS DO ESPORTE, 8., 2019, Natal. Anais... Natal, CBCE, 2019. Disponível em: https $/ /$ bit.ly/2CXBIK9. Acesso em: 31 de jul. 2020.

ROSA, Marcelo Victor da; OSORIO, Antônio Carlos do Nascimento; PRADO FILHO, Kleber; PASSAMANI, Guilherme Rodrigues. Fazendo gênero, fazendo enunciados: discursos sobre a homofobia na escola. Revista Periódicus, Salvador, v. 1, p. 455 - 467, nov. 2019. Disponível em: https://bit.ly/36hYd3j. Acesso em: 27 de set. 2020.

SALES, Ricardo Augusto J. As vivências de lazer dos homossexuais masculinos que vivem com o HIV/AIDS: alguns apontamentos históricos e sociais. In: XVII CONGRESSO BRASILEIRO DE CIÊNCIAS DO ESPORTE, 17., IV CONGRESSO INTERNACIONAL DE CIÊNCIAS DO ESPORTE, 4., 2011, Porto Alegre. Anais... Porto Alegre, CBCE, 2011. Disponível em: https:/bit.ly/2DpT2BG. Acesso em: 31 de jul. 2020.

SCOTT, Joan. Gênero: uma categoria útil de análise histórica. Revista Educação e Realidade, Porto Alegre, v. 20, n. 2, p. 71-99, jul./dez. 1995.Disponível em:https://bit.ly/2PdTLbT . Acesso em: 28 de jul. 2020 .

SERRANO, Jéssica Leite; CAMINHA, Iraquitan de Oliveira; GOMES, Isabelle Sena. Homens trans e atividade física: a construção do corpo masculino. Movimento, Porto Alegre, v. 25, p. 25007 , jan./dez.2019. Disponível em: https://bit.ly/3hKMsEM. Acesso em: 28 de jul. 2020.

SILVA, Alan Camargo; FERREIRA, Jaqueline. Homens no "limite" das dores na musculação de uma academia de ginástica de bairro popular: uma etnografia sobre formas plurais de expressão da masculinidade. Movimento, Porto Alegre, v. 22, n. 1, jan./mar. 2016. Disponível em: https:/bit.ly/3hF2Q9K. Acesso em: 28 de jul. 2020.

SILVA, Tomaz Tadeu da. Documentos de identidade: uma introdução às teorias de currículo. $2^{\mathrm{a}}$ ed. $9^{\mathrm{a}}$ reimpressão. Belo Horizonte: Autêntica, 2005.

WENETZ, Ileana; DORNELLES, Priscila Gomes. Sexualidade e Educação Física escolar: articulações (im)possíveis? In: XVII CONGRESSO BRASILEIRO DE CIÊNCIAS DO ESPORTE, 17., IV CONGRESSO INTERNACIONAL DE CIÊNCIAS DO ESPORTE, 4., 2011, Porto Alegre. Anais... Porto Alegre, CBCE, 2011. Disponível em: https://bit.ly/3fvsts8. Acesso em: 31 de jul. 2020.

WENETZ, Ileana; MACEDO, Christiane Garcia. Masculinidade (s) no balé: gênero e sexualidade na infância. Movimento, Porto Alegre, v. 25, p. 25081, jan./dez. 2019. Disponível em: https $/ /$ bit.ly/2X5HMS7. Acesso em: 28 de jul. 2020. 
WILLIAMS, James. Pós-estruturalis mo. 2a ed. Petrópolis: Editora Vozes, 2013.

\section{NOTAS DE AUTOR}

AGRADECIMENTOS - Não se aplica.

FINANCIAMENTO - Não se aplica.

CONSENTIMENTO DE USO DE IMAGEM - Não se aplica.

APROVAÇÃO DE COMITÊ DE ÉTICA EM PESQUISA - Não se aplica.

CONFLITO DE INTERESSES - Não se aplica.

\section{LICENCA DE USO}

Os autores cedem à Motrivivência - ISSN 2175-8042 os direitos exclusivos de primeira publicação, com o trabalho simultaneamente licenciado sob a Licença CreativeCommonsAttribution Non-Comercial ShareAlike (CC BY-NC SA) 4.0 International. Esta licença permite que terceiros remixem, adaptem e criem a partir do trabalho publicado, desde que para fins não comerciais, atribuindo o devido crédito de autoria e publicação inicial neste periódico desde que adotem a mesma licença, compartilhar igual. Os autores têm autorização para assumir contratos adicionais separadamente, para distribuição não exclusiva da versão do trabalho publicada neste periódico (ex.: publicar em repositório institucional, em site pessoal, publicar uma tradução, ou como capítulo de livro), com reconhecimento de autoria e publicação inicial neste periódico, desde que para fins não comerciais e compartilhar com a mes ma licença.

\section{PUBLISHER}

Universidade Federal de Santa Catarina. Programa de Pós-Graduação em Educação Física. LaboMídia Laboratório e Observatório da Mídia Esportiva. Publicado no Portal de Periódicos UFSC. As ideias expressadas neste artigo são de responsabilidade de seus autores, não representando, necessariamente, a opinião dos editores ou da universidade.

\section{EDITORES}

Mauricio Roberto da Silva, Giovani De Lorenzi Pires, Rogério Santos Pereira.

EDITOR DE SEÇÃO

Rafael Matiuda Spinelli

REVISÃO DO MANUSCRITO E METADADOS

João Caetano Prates Rocha; Keli Barreto Santos

\section{HISTÓRICO}

Recebido em: 08 de agosto de 2020

Aprovado em: 29 de setembro de 2020 